\title{
Analysis of Flagellin Perception Mediated by flg22 Receptor OsFLS2 in Rice
}

\author{
Ryota Takai, ${ }^{1}$ Akira Isogai, ${ }^{1}$ Seiji Takayama, ${ }^{1}$ and Fang-Sik Che $^{2}$ \\ ${ }^{1}$ Graduate School of Biological Sciences, Nara Institute of Science and Technology (NAIST), 8916-5, Takayama Ikoma, \\ Nara 630-0191, Japan; ${ }^{2}$ Graduate School of Bio-Science, Nagahama Institute of Bio-Science and Technology, 1266 , \\ Tamura Nagahama, Shiga 526-0829, Japan
}

Submitted 26 April 2008. Accepted 23 August 2008.

\begin{abstract}
Plants have sensitive perception systems that recognize various pathogen-derived molecules. We previously reported that rice detects flagellin from a rice-incompatible strain of gram-negative phytopathogenic bacterium, Acidovorax avenae, which induces subsequent immune responses involving cell death. The mechanism of flagellin perception in rice, however, has remained obscure. In this study, we found that flg22, a peptide derived from the flagellin $\mathrm{N}$-terminus, induced weak immune responses without cell death in cultured rice cells. To elucidate the mechanism by which flg22 induced signaling in rice, we characterized OsFLS2, the rice ortholog of AtFLS2, which mediates flg22 perception. Heterologous expression of OSFLS2 functions in Arabidopsis, showing the conservation of the flg22 signaling pathway across divergent plant taxa. OsFLS2-overexpressing rice cultured cells generated stronger immune responses with the induction of cell death following stimulation with flg22 and flagellin. However, examination of the growth rate of the compatible strain in inoculated OsFLS2-overexpressing rice could not confirm bacterial growth suppression compared with wild-type rice. These results suggest that rice possesses a conserved flagellin perception system utilizing the FLS2 receptor which, when upregulated, hardly affects resistance against compatible $A$. avenae.
\end{abstract}

Additional keywords: MAMPs, OsNAC4.

Throughout natural history, plants have been continually exposed to a variety of microorganisms, including potential pathogens. As a result, these species have evolved intricate defense mechanisms to protect themselves. Disease resistance in plants depends heavily on two systems, gene-for-gene and microbe-associated molecular patterns (MAMPs; also called PAMPs) recognition pathways (Bent and Mackey 2007). In gene-for-gene resistance, plant resistance (R) proteins specifically recognize factors with particular avirulence (Avr) proteins from pathogens either indirectly, through detection of changes in host protein targets, or directly, by interacting with $\mathrm{R}$ and Avr proteins. In contrast to gene-for-gene resistance, MAMPmediated resistance is a broader perception system that identifies molecular motifs characteristic of entire groups or classes of microorganisms. Flagellin, one of the main components of

Corresponding author: F. S. Che; Telephone: +81-749-64-8162; Fax: +81749-64-8140; E-mail: k_sai@nagahama-i-bio.ac.jp

* The $\boldsymbol{e}$-Xtra logo stands for "electronic extra" and indicates a supplemental figure is published online. bacterial flagella, is recognized as a MAMP by plants (GómezGómez and Boller 2002). In Arabidopsis, flagellin is recognized by the most conserved domain in its $\mathrm{N}$-terminus, represented by the flg22 22-amino-acid (aa) peptide (Felix et al. 1999). Detection of this elicitor-active domain depends on the FLS2 (flagellin sensing 2) protein (Gómez-Gómez and Boller 2000). Arabidopsis FLS2 (AtFLS2) encodes a receptorlike kinase (RLK) with an extracellular leucine-rich repeat (LRR), a single membrane-spanning domain, and a cytoplasmic serine/threonine kinase domain. Specific interaction of flg22 with AtFLS2 has been demonstrated by chemical crosslinking and immunoprecipitation, suggesting that AtFLS2 is responsible for the specificity of flagellin perception (Chinchilla et al. 2006).

Acidovorax avenae (Pseudomonas avenae) is a gram-negative phytopathogenic bacterium that causes brown stripes in susceptible plants. A. avenae can infect a wide range of host monocotyledonous plants, including rice, oat, Italian millet, and maize; individual strains of the pathogen, however, can only infect one or a few host species (Kadota et al. 1991, 1996). We previously reported that a rice-incompatible strain, N1141, induced immune responses, including hypersensitive response (HR) cell death, generation of reactive oxygen species (ROS), and activation of defense-related genes, in cultured rice cells, whereas the rice-compatible strain K1 did not (Che et al. 1999; Fujiwara et al. 2004; Iwano et al. 2002; Tanaka et al. 2001, 2003). To identify the molecule responsible for recognition in this rice immune system, we raised a strain-specific antibody against the incompatible strain. After absorption with the compatible strain, the specific antibody detected flagellin, which possesses structural differences between compatible and incompatible A. avenae strains (Che et al. 2000). Flagellin purified from a rice-incompatible strain, N1141, specifically induced immune responses in cultured rice cells, whereas no immune response was observed following treatment with purified compatible K1 flagellin (Che et al. 2000; Tanaka et al. 2003). In this system, flagellin derived from $A$. avenae appears to function as an avirulent protein rather than a MAMP.

On the other hand, suspension cultures of rice have not demonstrated detectable responses to flg22 (Felix et al. 1999), as we also confirmed previously (Takai et al. 2007). Thus, it is unclear why flg22 does not function as a MAMP in rice. In this article, to understand flagellin perception in rice, we initially examined the elicitor activity of flg22 in rice by using a more sensitive system. We then identified OsFLS2, the rice ortholog of AtFLS2, which remains capable of recognizing flg22. We also demonstrated that overexpression of OsFLS2 enhances rice immune responses involving cell death but does not affect the resistance against the $A$. avenae-compatible $\mathrm{K} 1$ strain. 


\section{RESULTS}

Analysis of the flg22 activity in cultured rice cells.

Amino acid sequences similar to flg22 also exists in the $\mathrm{N}$ termini (residues 30 to 51) of A. avenae N1141 and K1 flagellins. These sequences are identical and differ in 4 aa from the flg22 sequence (Fig. 1A). We generated both flg22 and flg22avenae, the peptide corresponding to flg22 within the A. avenae flagellin.

The oxidative burst is one of the earliest responses activated following MAMPs recognition (Bolwell et al. 1995; Lamb and Dixon 1997). To determine the elicitor activity of these peptides, we measured ROS generation using a luminol-based chemiluminescence detection system (Schwacke and Hager 1992). Both flg22 and flg22-avenae induced low levels of

\section{A fIg22:QRLSTGSRINSAKDDAAGLQIA flg22-avenae:QRLSŠGL ${ }^{\star}$ RINSAKDDAAGLÅIS}
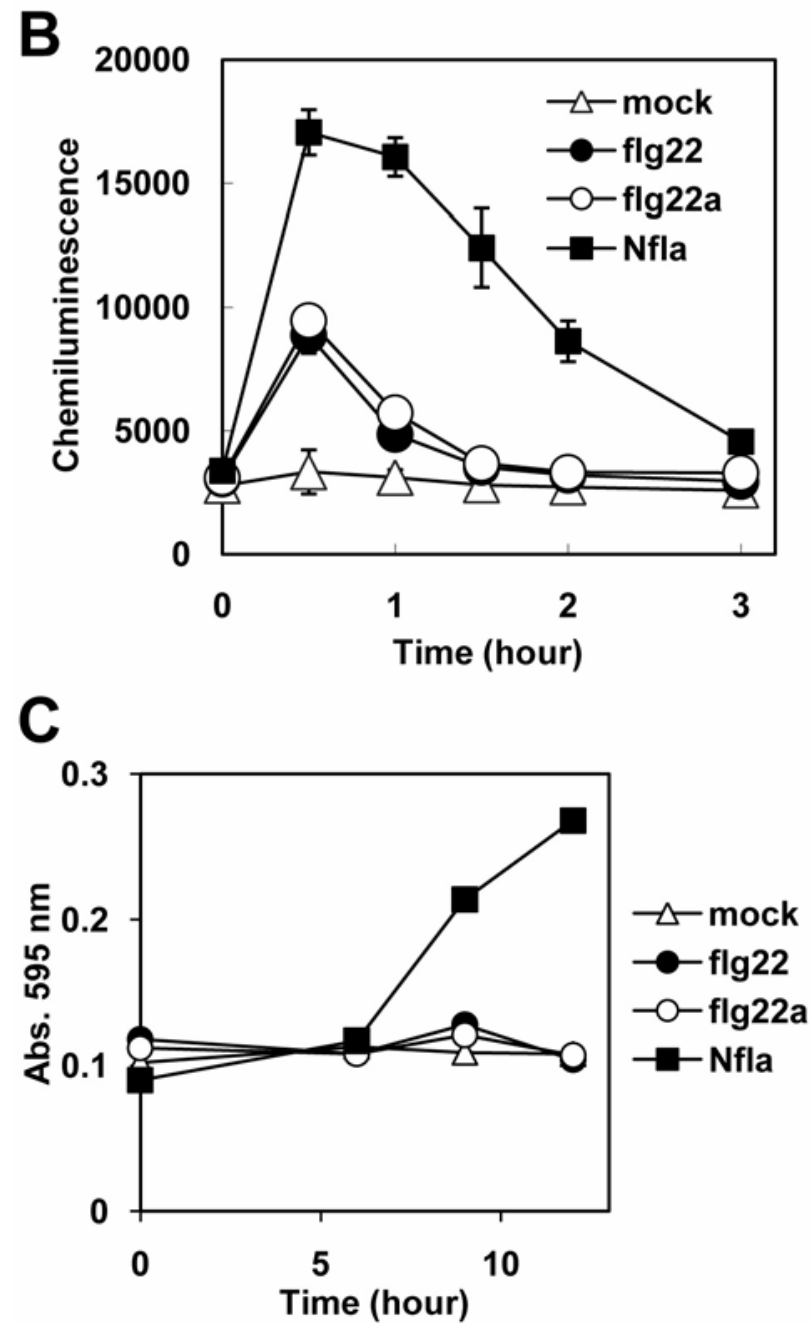

Fig. 1. The flg22 peptide induces immune responses in rice. A, Amino acid sequence comparison of flg22 and flg22-avenae, which is derived from Acidovorax avenae flagellin. Asterisks indicate amino acids that differ between flg22 and flg22-avenae. B, Reactive oxygen species (ROS) generation induced by treatment with $500 \mathrm{nM}$ N1141 flagellin (Nfla), flg22, or flg22-avenae (flg22a) in cultured rice cells. ROS were detected using a luminolchemiluminescence assay. Error bars indicate the standard deviations for all data. C, Time course of cell death induced by treatment with $500 \mathrm{nM}$ N1141 flagellin, flg22, or flg22-avenae. The proportion of cell death was estimated by Evans blue staining of cells at an absorbance of $595 \mathrm{~nm}$. transient ROS generation in cultured rice cells (Fig. 1B). The elicitor activities of these peptides, however, were weaker than that seen with full-length flagellins purified from the A. avenae N1141 strain. We previously reported that purified N1141 flagellins induced HR cell death in cultured rice cells (Che et al. 2000). In contrast, no cell death was observed within $12 \mathrm{~h}$ of the addition of flg22 and flg22-avenae to cultured rice cells (Fig. 1C). The incompatible N1141 flagellin induced obvious cell death within $9 \mathrm{~h}$ of treatment; therefore, flg22 and flg22avenae did not appear to induce significant HR cell death in cultured rice cells. These results suggest that the flg22 region of $A$. avenae flagellin lacks the majority of the elicitor activity possessed by a whole flagellin from the incompatible N1141 strain.

\section{Identification of rice FLS2 homolog.}

In Arabidopsis, flg22 recognition is mediated by the LRR receptor kinase AtFLS2 (Gómez-Gómez and Boller 2000). To clarify why, in cultured rice cells, the flg22 region lacks most of the elicitor activity present for the full-length protein, we searched for a rice homolog of AtFLS2 in the rice full-length cDNA database. We identified a cDNA (AK120799) that encoded a protein with $45 \%$ amino acid identity to AtFLS2. Because other LRR receptor kinase genes exhibited less than 36\% identity with AtFLS2, the AK120799 gene was a promising candidate for the flg22 receptor in rice. This cDNA sequence had an open reading frame of 3,522 bp encoding a predicted protein of 1,174 aa, similar in length to AtFLS2 $(1,173$ aa). The deduced amino acid sequence of AK120799 contained a signal sequence, an extracellular LRR domain, a transmembrane domain, and a serine/threonine kinase domain (Fig. 2). Sequence alignment with AtFLS2 and LeFLS2 (tomato ortholog of AtFLS2) (Robatzek et al. 2007) revealed that AK120799 contained an LRR domain of 27 tandem repeats, which is 1 repeat less than At and LeFLS2, and several insertions in N-terminus and kinase domain (Supplemental Fig. 1). mRNA expression of AK120799 could be detected in rice root, leaf-, and suspension-cultured cells (data not shown).

To examine whether AK120799 has a function equivalent to that of Arabidopsis FLS2, we performed complementation analysis after transient expression in protoplasts isolated from Arabidopsis fls 2 mutant leaves. We cotransformed the Cauliflower mosaic virus (CaMV) 35S promoter-driven AK120799 expression vector with the AtWRKY29-luc reporter plasmid. As previously reported (Asai et al. 2002), AtWRKY29-luc was activated by flg22 treatment in wild-type protoplasts but not the fls 2 mutant (Fig. 3). Transient expression of AK120799 or AtFLS2 restored flg22-inducibility of the AtWRKY29 promoter in fls 2 mutant protoplasts (Fig. 3), indicating that AK120799 encodes the AtFLS2 ortholog in rice. Therefore, we designated this gene (AK120799) OsFLS2.

OSFLS2 shows different selectivity toward flg22 derivative.

The flg $22 \Delta 2$ peptide, which is shortened by two amino-acid residues at its $\mathrm{C}$-terminus, lacks any agonist activity and exhibits antagonistic activity in Arabidopsis (Bauer et al. 2001). We examined the ability of flg $22 \Delta 2$ to induce the generation of ROS in rice. Although flg $22 \Delta 2$ has a 10 -fold weaker agonist activity than that of flg 22 in rice, we did not observe any antagonistic activity against flg22 (Fig. 4A). To examine if difference in our observed response from that previously reported was attributable to different features of AtFLS2 and OsFLS2, we transiently transformed AtFLS2 or OsFLS2 expression vector with the AtWRKY29-luc reporter into protoplasts isolated from Arabidopsis fls 2 mutants. After treatment with flg22 or flg22 22 , expression of AtFLS2 conferred flg22-sensitive and flg22 $\Delta 2$-insensitive Arabidopsis-type perception, 
while OsFLS2 provided flg22- and flg22 $\Delta 2$-sensitve rice-type perception (Fig. 4B). These results demonstrated that the subtype of FLS2 receptor determines the specificity of flagellin (flg22) perception.

\section{Transient overexpression of OsFLS2 enhances} flg22 responsiveness on rice line Oc cells.

Although rice has a flg22 perception system, flg22 was only able to induce a weak immune response (Fig. 1B and C). We

\section{Signal peptide MSQHYTKTICIAVVLVAVLFSLSSA}

N-terminus

AAAGSGAAVSVQLEALLEFKNGVAD DPLGVLAGWRVGKSGDGAVRGGALP RHCNWTGVACDGAGQVTSIQLPESKLRGALSPF

LRR domain

LGNISTLQVIDLTSNAFAGGIPPQ

LGRLGELEQLVVSSNYFAGGIPSS LCNCSAMWALALNVNNLTGAIPSC IGDLSNLEIFEAYLNNLDGELPPS MAKLKGIMVVDLSCNQLSGSIPPE IGDL̈SNLQILQLYENRFSGHIPRE LGRCKNLTLLNIFSNGGTGEIPGE LGELTNLEVMRLYKNALTSEIPRS LRRCVSLLNLDLSMNQLAGPI PPE LGELPSLQRLSLHANRLAGTVPAS LTNLVNLTILELSENHLSGPLPAS IGSLRNLRRLIVQNNSLSGQIPAS ISNCTQLANASMSFNLFSGPLPAG LGRLQSLMFLSLGQNSLAGDIPDD LFDCGQLQKLDLSENSFTGGLSRL VGQLGNLTVLQLQGNALSGEIPEE IGNMTKLISLKLGRNRFAGHVPAS ISNMSSLQLLDLGHNRLDGVFPAE VFELRQLTILGAGSNRFAGPIPDA VANLRSLSFLDLSSNMLNGTVPAA LGRLDQLLTLDLSHNRLAGAIPGAVI ASMSNVQMYLNLSNNAFTGAIPAE IGGLVMVQTIDLSNNQLSGGVPAT LAGCKNLYSLDLSGNSTTELPANL FPQLDLLTTLNISGNDLDGEIPAD IAALKHIQTLDVSRNAFAGAIPPA LANLTALRSLNLSSNTFEGPVPDG

extracellular GVFRNLTMSSLQGNAGLCGGKLLAPCH juxtamembrane GHAAGKKRVFSRTG

transmembrane LVILVVLIALSTLLLLMVATILI

intracellular VSYRRYRRKRRAADIAGDSPEAAVVVPE juxtamembrane LRRFSYGQLAAATNS

S/T kinase FDQGNVIGSSNLSTVYKGVLAGDADGGMVVAVKRLNLEQF domain PSKSDKCFLTELATLSRLRHKNLARVVGYAWEAGKIKALV LDYMVNGDLDGAIHGGAAAPPPAPSRWTVRERLRVCVSVA HGLVYLHSGYDFPVVHCDVKPSNVLLDGDWEARVSDFGTA RMLGVHLPAAANAAAQSTATSSAFRGTVGYMAPEFAYMRT VSTKVDVFSFGVLAMELFTGRRPTGTIEEDGVPLTLQQLV DNAVSRGLDGVHAVLDPRMKVATEADLSTAADVLAVALSC AAFEPADRPDMGAVLSSL

\section{C-terminus}

LKMSKLVGED

Fig. 2. Deduced amino acid sequence of OsFLS2 cDNA (accession number AK120799). Indicated are the predicted signal peptide, N-terminal domain, leucine-rich repeat (LRR) domain, extracellular juxtamembrane region, single transmembrane domain, intracellular juxtamembrane region, serine/threonine (S/T) kinase domain, and C-terminal tail. Residues matching the LRR consensus sequence are marked in gray boxes. hypothesized that upregulation of OsFLS2 protein levels might mediate stronger immune responses to flg22. Therefore, we examined whether OsFLS2 overexpression in rice enhanced an immune response induced by flg22 treatment. We used a transient expression assay in rice protoplasts using the flagellinresponsive rice gene OsWRKY70 as a reporter (Takai et al. 2007). The CaMV 35S promoter-driven OsFLS2 expression vector was cotransformed into rice protoplasts with the $O s$ WRKY70 promoter-driven luciferase reporter. Overexpression of OsFLS2 mRNA in transformed cells was checked by realtime polymerase chain reaction (PCR) (data not shown). Transformed cells were treated with flg22 or N1141 flagellin for $6 \mathrm{~h}$, then assayed by dual luciferase assay. Flg22 inducibility of the OsWRKY promoter did not occur in rice protoplasts transformed with control vector, but flg22 responsiveness was easily detected following transient overexpression of OsFLS2 (Fig. 5). This result suggested that the low sensitivity of rice to flg22 might be due to low levels of OsFLS2 protein, not defects in the signaling pathways downstream of OsFLS2.

Overexpression of OsFLS2 in rice caused strong immune responses involving cell death by flagellin and flg22.

To analyze the effect of OsFLS2 on immune responses, we generated stable transgenic rice that overexpressed OsFLS2 cDNA driven by the CaMV 35S promoter. The expression levels of OsFLS2 mRNA in OsFLS2-overexpressing rice cells (OsFLS2-ox) were approximately 100-fold higher than those seen in control rice cells transformed with empty vector (Fig 6A). We confirmed that the polyclonal antibody raised against the C-terminal peptide of OsFLS2 specifically detected a polypeptide with an apparent molecular mass of $\approx 170,000$ in microsomal fractions (Fig 6B). Because OsFLS2 encodes a polypeptide of $121 \mathrm{kDa}$, OsFLS2 may be glycosylated at several of its 16 potential $\mathrm{N}$-glycosylation sites $(\mathrm{N}-\mathrm{X}-\mathrm{S} / \mathrm{T})$ within the LRR domain. Similar discrepancies between estimated and actual molecular weight due to glycosylation have been reported for AtFLS2 (Chinchilla et al. 2006).

We used suspension-cultured transformants to assay several aspects of the immune response. Analysis of ROS generation

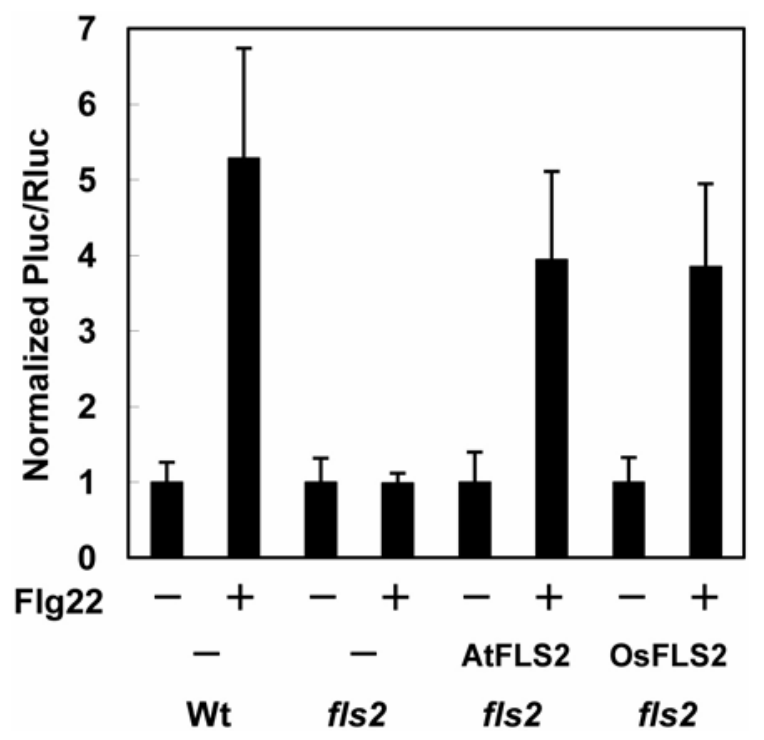

Fig. 3. OsFLS2 restores flg 22 responsiveness in Arabidopsis fls 2 mutants. Protoplasts isolated from Arabidopsis wild-type or fls2 mutant leaves were transformed with pAtWRKY29-luc, phRluc, and additional constructs as indicated. Transformed protoplasts were pre-incubated for $10 \mathrm{~h}$ before incubation in the presence or absence of $100 \mathrm{nM}$ flg22 for $5 \mathrm{~h}$. Promoter activities are represented as the ratio of firefly to renilla luciferase activities after normalization to values obtained with mock treatment. 
demonstrated that OsFLS2-ox cells were more sensitive to flg22 than rice cells transformed with control vector, exhibiting significantly more robust responses (Fig. 7A). We also observed the induction of the OsNAC4 gene (Kaneda et al. 2007), which is involved in HR cell death, following flg22 treatment of OsFLS2-ox but not control cells (Fig. 7B). We also examined the induction of cell death in OsFLS2-ox cells following treatment with flg22 and flagellins purified from the incompatible N1141 and compatible K1 strains of A. avenae. Overexpression of OsFLS2 evoked significant cell death in response to the tested flagellins (Fig. 7C). Surprisingly, both flg22 and K1 flagellin, which do not induce such activity in wild-type rice cells, induced obvious cell death in OsFLS2-ox cells, indicating that levels of the FLS2 flagellin receptor can control the intensity of the immune response.

\section{Overexpression of OsFLS2 did not affect the resistance} against compatible $\mathrm{K} 1$ strain.

We show here that overexpression of a flagellin receptor, OsFLS2, led to the enhancement of immune responses to flagellins (Figs. 5 and 7). Thus, we expected that OsFLS2-ox rice showed increased disease resistance to $A$. avenae. The
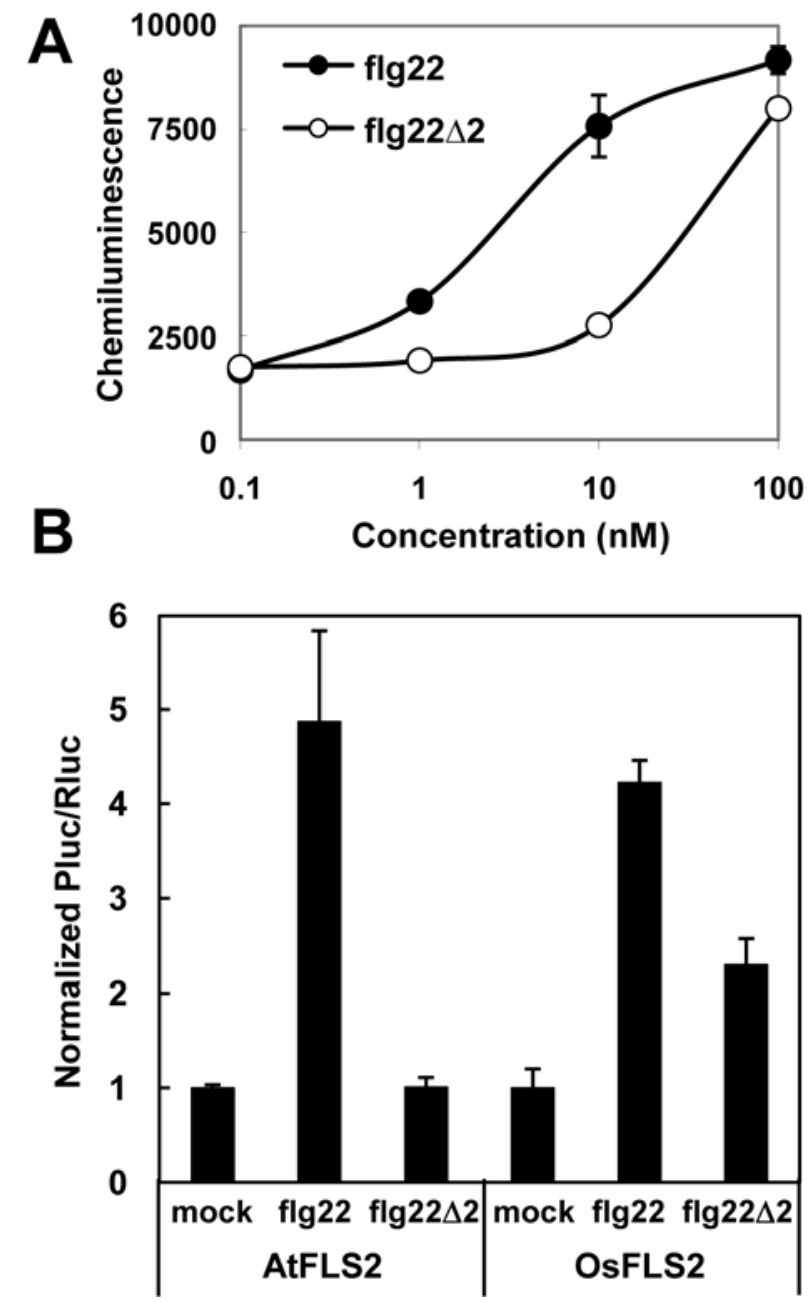

Fig. 4. Heterologous expression of OsFLS2 in Arabidopsis confers ricetype flagellin perception specificity. A, Dose-response curves for reactive oxygen species (ROS) generation induced by flg 22 or flg $22 \Delta 2$ treatment. ROS production was analyzed at 30 min after treatment with $0.1,1,10$, or $100 \mathrm{nM}$ flg22 or flg22 2 . B, Protoplasts isolated from Arabidopsis fls 2 mutant leaves were transformed with pAtWRKY29-luc, phRluc, and additional constructs as indicated. Transformed protoplasts were pre-incubated for $10 \mathrm{~h}$ before incubation in the presence or absence of $100 \mathrm{nM}$ flg 22 or flg $22 \Delta 2$ for $5 \mathrm{~h}$.

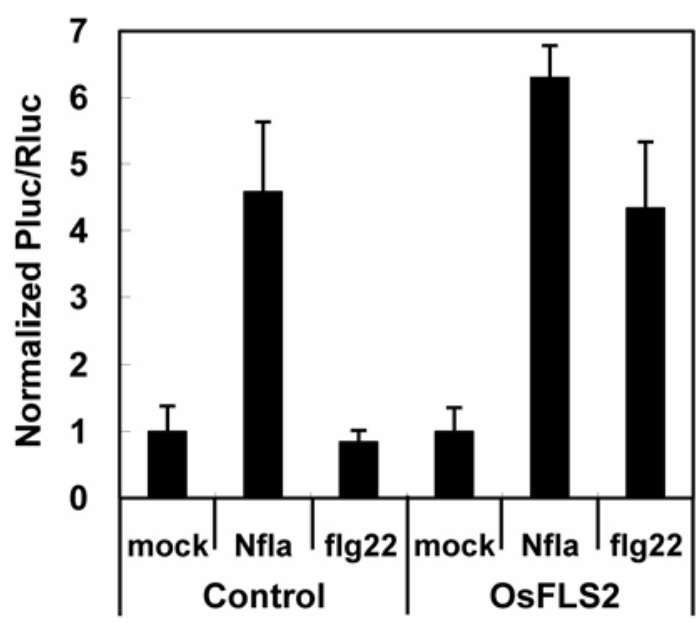

Fig. 5. Transient overexpression of OsFLS2-enhanced flg22 responsiveness in rice. Protoplasts isolated from rice Oc cells were transformed with pOsWRKY70-luc, phRluc, and additional constructs as indicated. Transformed protoplasts were pre-incubated for $12 \mathrm{~h}$ before incubation in the presence or absence of $300 \mathrm{nM}$ flg22 or N1141 flagellin (Nfla) for $6 \mathrm{~h}$.

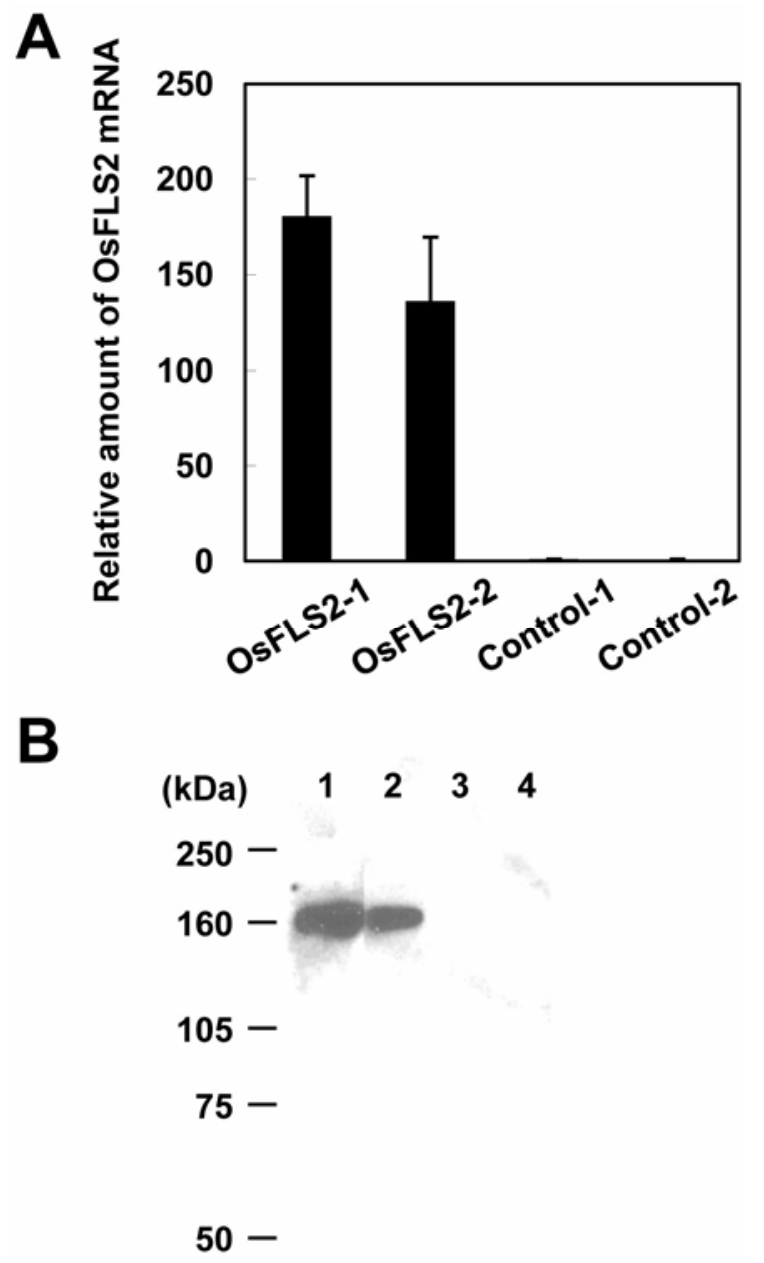

Fig. 6. Confirmation of OsFLS2 overexpression in 35S::OsFLS2 transgenic rice. A, $O s F L S 2$ mRNA levels were analyzed by real-time polymerase chain reaction of total RNA from 35S::OsFLS2-1, 35S::OsFLS2-2, control-1, and control-2 rice cells. Expression levels are displayed as the fold change in expression compared with control cells, which were normalized to values of one. B, Immunoblot analysis of OsFLS2 protein levels in microsomal fractions purified from transgenic lines 35S::OsFLS2-1 (lane 1), 35S::OsFLS2-2 (lane 2), control-1 (lane 3), and control-2 (lane 4). 
incompatible N1141 strain of A. avenae induced robust cell death of rice cultured cells but the compatible K1 strain did not (Che et al. 2002). We examined the induction of cell death in OsFLS2-ox-cultured cells following inoculation with $\mathrm{N} 1141$ and $\mathrm{K} 1$ strains of A. avenae. OsFLS2-ox cells exhibited responses to $\mathrm{N} 1141$ and $\mathrm{K} 1$ strains similar to that in control cells (Fig. 8A), suggesting that overexpression of OsFLS2 did not enhance the induction of cell death in response to N1141 and K1 strains.

Next, we also examined whether OsFLS2-ox rice plants enhanced the resistance against $A$. avenae. The A. avenae-incompatible N1141-strain-inoculated rice plants showed localized browning of tissue around the inoculation point, which was assumed to be HR (Che et al. 1999). In contrast, the compatible K1 strain causes a seedling disease characterized by the formation of brown stripes which correlates with bacterial growth in the rice (Che et al. 1999; Tanaka et al. 2003). OsFLS2-ox rice plants, which showed normal growth and morphology, were inoculated with the N1141 or K1 strain using a single-needle method (Kadota et al. 1996). When OsFLS2-ox plants were inoculated with the N1141 strain, slight growth suppression was observed compared with control rice plants (Fig. 8B). In contrast, the compatible $A$. avenae $\mathrm{K} 1$ strain grew at the same rate in both the OsFLS2-ox and control rice plants (Fig. 8B). These results suggest that overexpression of OsFLS2 in rice did not provide resistance against the compatible K1 strain.

\section{DISCUSSION}

In this study, flg22, a 22-aa peptide within the N-terminus of flagellins, induced the generation of low levels of ROS in suspension-cultured rice Oc and Kinmaze (Japonica cultivar) cells. We confirmed that suspension-cultured cells from indica rice $\mathrm{cv}$. Kasalath also responded to flg22 (data not shown). We identified the flg22 receptor, OsFLS2, in the japonica rice genome and an OsFLS2-like gene (amino acid identity 99\%) in the indica rice genome. These results indicate that monocotyledonous as well as dicotyledonous rice possesses a flg22 perception system. It was previously reported that $\mathrm{flg} 22 \mathrm{did}$ not exhibit elicitor activity in rice suspension-cultured cells (Felix et al. 1999) and in rice protoplasts (Takai et al. 2007). Because both luminol assay using suspension-cultured cells and transient expression assay using protoplasts were performed using same rice cv. Oc cells, we speculate that this discrepancy is due to difference of sensitivity. Furthermore, we feel that the experimental condition of suspension-cultured rice cells is important for assaying flg22 activity.

Flagellin purified from the rice-compatible K1 strain does not demonstrate elicitor activity (Che et al. 2000). The flg22 sequence of K1 flagellin is identical to that of N1141 flagellin, suggesting that N1141 flagellin has an epitope in addition to the flg22 region capable of eliciting immune responses. Similar observations have been reported for flagellin from $P$. syringae.
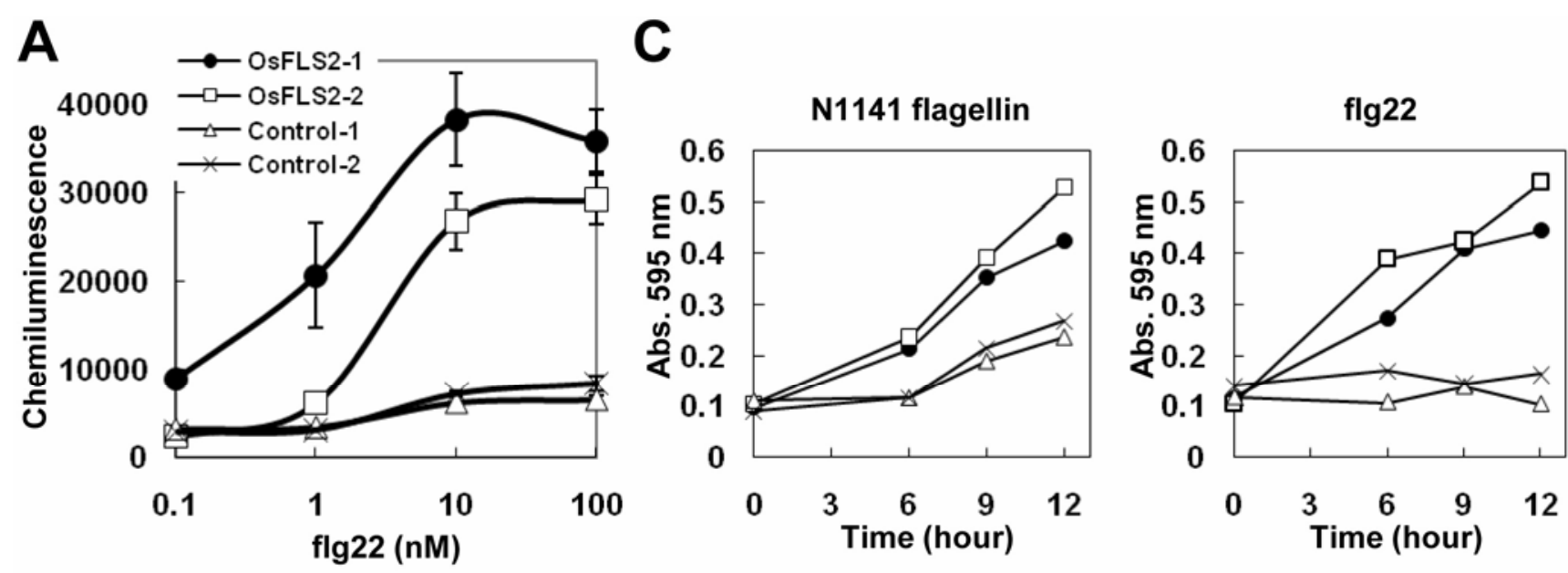

B
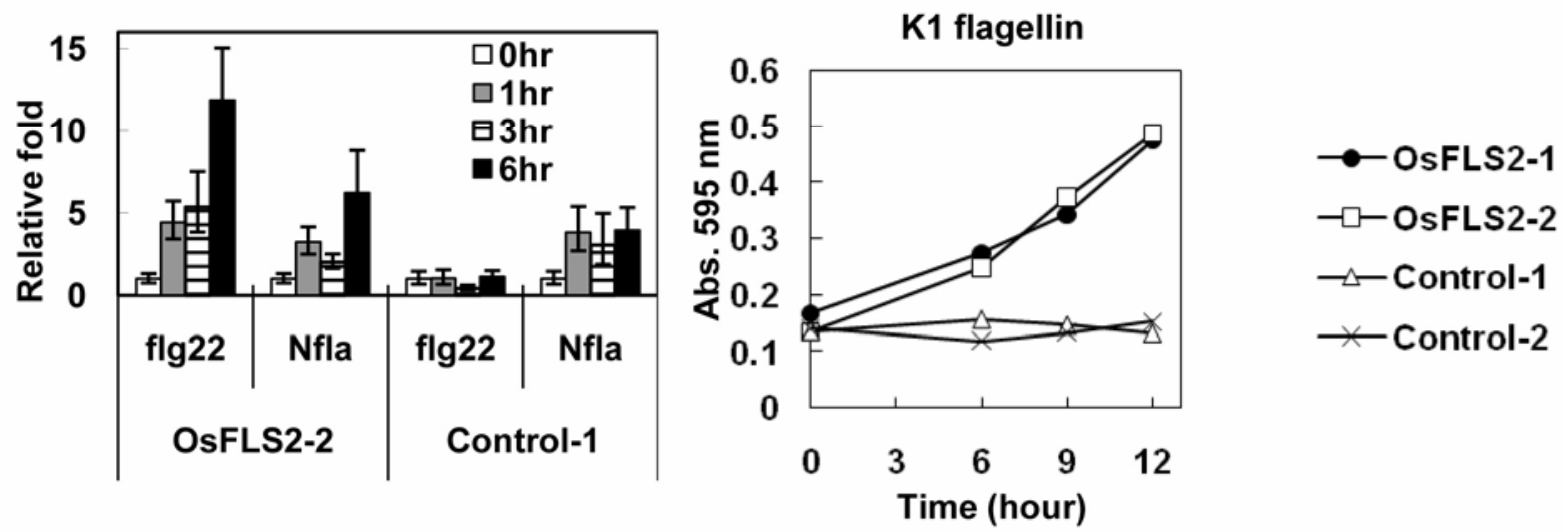

Fig. 7. Analysis of the stable transformants overexpressing OsFLS2. A, Dose-response curves for reactive oxygen species (ROS) generation induced by flg22 treatment. ROS production was analyzed at $30 \mathrm{~min}$ after treatment with $0.1,1,10$, or $100 \mathrm{nM}$ flg 22 . B, Induction of $O$ sNAC4 gene expression by $500 \mathrm{nM}$ flg22 or N1141 flagellin (Nfla). OsNAC4 mRNA levels were analyzed at 0, 1, 3, and $6 \mathrm{~h}$ after elicitor treatment (shown in white, gray, striped, and black bars, respectively). Expression levels are displayed as the fold change from that seen in nontreated cells, which were normalized to values of one. $\mathbf{C}$, Time course of cell death induced by $500 \mathrm{nM}$ flg22, N1141 flagellin, or K1 flagellin as measured by Evans blue staining of individual cells at an absorbance of 595 nm. 
Flagellins purified from $P$. syringae pv. glycinea, an incompatible pathogen for tobacco, induced immune responses in tobacco, whereas flagellin from pv. tabaci, a compatible pathogen, does not, despite complete amino acid identity (Taguchi et al. 2003). The differential glycosylation of flagellin may provide clues to understanding this phenomenon (Ishiga et al. 2005). Flagellin proteins from the N1141 and K1 strains are also modified by glycosylation (Che et al. 2000) (unpublished result), indicating that determining glycosylation sites and carbohydrate structures are important for future research.

In this study, we identified the rice LRR kinase OsFLS2, which is highly homologous to AtFLS2 and functions in flg22 perception (Figs. 2 and 3). In addition to those found in rice and Arabidopsis, an FLS2 gene was recently identified in tomatoes (Robatzek et al. 2007), tobacco (Hann and Rathjen 2007), and Brassica spp. (Dunning et al. 2007). Expression of OsFLS2 in the Arabidopsis fls 2 mutant restores the induction of immune responses following flg22 treatment; therefore, it appears capable of interacting with downstream signaling components in Arabidopsis. These findings indicate the conservation of flg22-FLS2 signaling in monocots and dicots. OsFLS2 and AtFLS2, however, exhibit different responses to flg22 $\Delta 2$, a form of flg22 with the two C-terminal amino acids deleted (Fig. 4). We also found a peptide flg $22 \Delta \mathrm{A}^{16 / 17}$, lacking one of the alanine residues at position of 16 or 17 , that exhib-
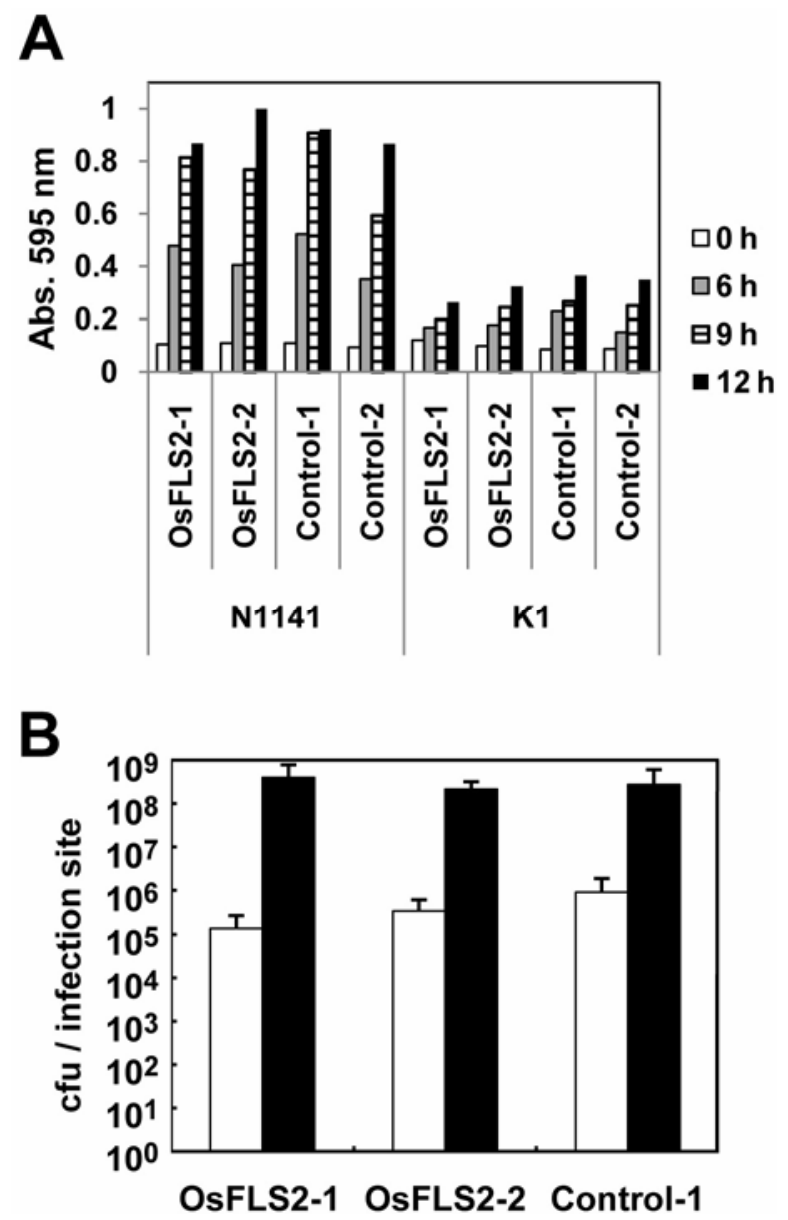

Fig. 8. Effects of overexpression of OsFLS2 on resistance to Acidovorax avenae in rice cells and seedlings. A, Time course of cell death in OsFLS2-ox or control cells inoculated with A. avenae N1141 $\left(10^{8} \mathrm{CFU}\right.$ $\left.\mathrm{ml}^{-1}\right)$ or $\mathrm{K} 1\left(10^{8} \mathrm{CFU} \mathrm{ml}{ }^{-1}\right)$ strain. B, A. avenae $\mathrm{N} 1141\left(10^{6} \mathrm{CFU}\right)$ or K1 strain $\left(10^{6} \mathrm{CFU}\right)$ were inoculated into 4-week-old OsFLS2-ox or control rice seedlings. White bars $=$ N1141 strain and black bars $=$ K1 strain. The numbers of bacterial cells were counted 7 days after inoculation. The values shown are averages of at least five independent experiments. ited a weak agonist activity in rice (data not shown), while the peptide acts as a competitive antagonist in tomato (Chinchilla et al. 2006). Differences in the recognition of the flg22 derivatives between plant families have been reported (Bauer et al. 2001; Chinchilla et al. 2006; Robatzek et al. 2007); therefore, the results of those previous works demonstrate that FLS2 functions as a primary receptor determining the specificity of flagellin perception. It can be speculated that differences in recognition of flg22 derivatives between plant species are due to sequence diversity in the LRR domain of FLS2.

In contrast to the immune responses mediated by gene-forgene disease resistance, the flg22 pathway does not induce an HR and cell death (Gómez-Gómez and Boller 2002). We confirmed that flg22 did not evoke cell death in suspension-cultured rice cells. Overexpression of OsFLS2 in rice cells, however, led to cell death after flg22 treatment (Fig. 7C). Thus, the induction of cell death appears to be regulated by differential signal intensity, not differing signaling patterns. Reaching a threshold concentration of signaling intermediates, such as intracellular $\mathrm{Ca}^{2+}$ or ROS, may be required for the activation of HR cell death. We observed here that the OsNAC4 gene was upregulated during cell death induction by flg22 treatment in OsFLS2overexpressing rice cells (Fig. 7B). OsNAC4 is a plant-specific transcription factor whose overexpression in rice induces cell death, accompanied by nuclear DNA fragmentation and morphological changes specific to HR cell death; downregulation of OsNAC4 by RNAi knockdown markedly decreases HR cell death in response to incompatible bacterial strains (T. Kaneda, Y. Taga, R. Takai, S. Takayama, A. Isogai, and F. Che unpublished result). Thus, OsNAC4 serves as a specific marker for $\mathrm{HR}$ cell death in rice.

Upregulation of MAMP receptors has been proposed as an approach to engineering disease resistance in plants (Gurr and Rushton 2005). However, examination of the growth rate of the compatible $A$. avenae $\mathrm{K} 1$ strain in inoculated OsFLS2overexpressing rice plants could not confirm bacterial growth suppression compared with wild-type rice (Fig. 8B). There are several possibilities to explain this discrepancy. One is that $A$. avenae might bypass the first steps of the natural infection process because bacteria were directly infiltrated into the intercellular leaf space by the needle method. It was reported that Arabidopsis fls 2 mutant plants exhibited more rapid and severe symptoms after spraying with $P$. syringae on the leaf surface but did not exhibit after directly infiltrating into leaves (Zipfel et al. 2004). Thus, it is speculated that flagellin perception restricts bacterial invasion at an early step. Another is that OsFLS2 may have only a small role in resistance to bacterial infection. Due to the unavailability of OsFLS2-deficient rice, we have not been able to test the importance of OsFLS2 in rice bacterial infections. It is also possible that a bacterial virulence factor or factors is able to overcome the host defenses enhanced by overexpression of OsFLS2. Several bacterial effectors introduced via a type III secretion system block host responses induced by MAMP perception (Grant et al. 2006). It may be difficult to produce plants with durable disease resistance by the simple method of upregulating this MAMP receptor. We will need to understand in greater detail the mechanism of this MAMP recognition system in rice to effectively engineering disease resistance.

\section{MATERIALS AND METHODS}

\section{Plants and bacteria.}

Suspension cultures of rice cells, line Oc, were grown at $30^{\circ} \mathrm{C}$ under light irradiation (Baba et al. 1986). The cells were diluted in fresh medium every week, and all experiments were performed 3 or 4 days after transfer. An Arabidopsis T-DNA 
insertion line in AtFLS2 (SALK_062054) was obtained from the Nottingham Arabidopsis Stock Centre (NASC; Nottingham, U.K.). A. avenae strains N1141 (MAFF 301141) and K1 (MAFF 301755) were as previously described (Che et al. 2000; Kadota et al. 1996).

\section{Purification of native flagellin.}

Flagellin was purified as previously described (Che et al. 2000) with the following modifications. A. avenae N1141 and $\mathrm{K} 1$ strains were grown for 1.5 days in Luria-Bertani medium at $30^{\circ} \mathrm{C}$ on a rotary shaker. Cells were harvested by centrifugation at $6,000 \times g$ for $20 \mathrm{~min}$ at $4^{\circ} \mathrm{C}$. Pellets were washed with $20 \mathrm{mM}$ Tris- $\mathrm{HCl}$ (pH 7.5) containing $150 \mathrm{mM} \mathrm{NaCl}$, collected by centrifugation, and resuspended in $15 \mathrm{ml}$ of the same buffer. Flagella were removed from cells by shearing in a homogenizer (Ultra F Homogenizer HF-93F; TAITEC, Saitama, Japan) for $3 \mathrm{~min}$. Intact cells and cellular debris were removed by twostep centrifugation at $6,000 \times g$ for $30 \mathrm{~min}$ and $16,000 \times g$ for $60 \mathrm{~min}$ at $4^{\circ} \mathrm{C}$. Flagella were collected by ultracentrifugation at $200,000 \times \mathrm{g}$ for $60 \mathrm{~min}$ at $4^{\circ} \mathrm{C}$. Pellets were resuspended in distilled water and stored at $-80^{\circ} \mathrm{C}$.

\section{Oligopeptides.}

The flg22 (QRLSTGSRINSAKDDAAGLQIA), flg22-avenae (QRLSSGLRINSAKDDAAGLAIS), and flg22 2 (QRLSTGSR INSAKDDAAGLQ) oligopeptides were synthesized at Peptide Institute, Inc. (Osaka, Japan) or Sigma-Aldrich Japan (Tokyo).

\section{$\mathrm{H}_{2} \mathrm{O}_{2}$ detection and quantification.}

We monitored the generation of ROS in medium from cultured cells by measuring chemiluminescence due to the ferricianide-catalyzed oxidation of luminol (5-amino-2,3 dihydro1,4-phthalazinedione) as described by Schwacke and Hager (1992). Cultured cells (10 mg) were pre-incubated with $1 \mathrm{ml}$ of fresh media for $2 \mathrm{~h}$ at $30^{\circ} \mathrm{C}$. Cultured cells were incubated at $30^{\circ} \mathrm{C}$ with elicitors $(<100 \mu \mathrm{l})$ for variable periods after treatment. Following incubation, $10 \mu \mathrm{l}$ of medium was mixed with $160 \mu \mathrm{l}$ of $50 \mathrm{mM}$ potassium phosphate buffer $(\mathrm{pH} 7.9), 10 \mu \mathrm{l}$ of $1.1 \mathrm{mM}$ luminol, and $20 \mu \mathrm{l}$ of $14 \mathrm{mM}$ potassium ferricianide, then analyzed immediately for chemiluminescence using a Genelight55 lumi-counter (Microtec Co., Ltd., Chiba, Japan).

\section{RNA isolation and real-time PCR.}

Total RNAs were isolated from cultured rice cells using an RNeasy plant mini kit (Qiagen, Hilden, Germany) according to the manufacturer's instructions. Real-time PCR was performed using an ABI PRISM 7000 sequence detection system (Applied Biosystems, Foster City, CA, U.S.A.) with a QuantiTect SYBR Green RT-PCR Kit (Qiagen) and the following gene-specific primers: OsFLS2 (accession number AK120799) forward (5'GCGACGTCAAGCCGTCCAAC-3') and reverse (5'-CGACA CCGTCCTCATGTACGCGAA-3'), OsNAC4 (accession number AB028183) forward (5'-TCCTGCCACCATTCTGAGATG-3') and reverse (5'-TTGCAGAATCATGCTTGCCAG-3'), and Rice Actin 1 (accession number AB047313) forward (5'-TCCATCT TGGCATCTCTCAG-3') and reverse (5'-TGGCTTAGCATTC TTGGGTC-3'). Each set of samples was normalized to Rice Actin 1 levels as an internal control.

\section{Plasmid constructs.}

We amplified a 2.7-kb DNA fragment immediately upstream of the translation start site of Arabidopsis WRKY29 by PCR using Arabidopsis genomic DNA as a template. The PCR product was ligated into the HindIII-NcoI site of the pPluc plasmid (An et al. 2003) to generate the firefly (Photinus pyralis) luciferase (luc+; Promega Corp., Madison, WI, U.S.A.) reporter plasmid pAtWRKY29-luc. Construction of pOsWRKY70-luc reporter plasmid, used to assay elicitor activity in rice, has been described previously (Takai et al. 2007). AtFLS2 (At5g46330) and OsFLS2 (AK120799) cDNAs were acquired by PCR from an Arabidopsis cDNA library and a rice full-length cDNA clone (J023012H18), respectively. PCR products were inserted between the CaMV $35 \mathrm{~S}$ promoter and NOS terminator on $\mathrm{pBI} 221$ base vector. All constructs were verified by sequencing.

\section{Protoplast transient expression assay.}

Protoplast isolation and transient transformation using Arabidopsis leaves were performed as described previously (Sheen 2001). Protoplast isolation and transient transformation using suspension-cultured rice cells were carried out as described previously (Takai et al. 2007). A CaMV 35S promoterdriven sea pansy (Renilla reniformis) luciferase (hRluc; Promega Corp.) vector, phRluc (An et al. 2003), was cotransformed as an internal control for dual luciferase assays. Promoter activities were expressed as firefly luciferase/renilla luciferase activities and normalized to the values obtained in the absence of treatment.

\section{Production of OsFLS2-overexpressed rice.}

A 3.5-kb fragment containing the entire coding sequence of OsFLS2 cDNA was amplified by PCR and cloned downstream of the CaMV 35S promoter in the pCAMBIA1300 vector (CAMBIA, Canberra, Australia). This construct was introduced into Agrobacterium tumefaciens EHA105 by electroporation. Agrobacterium spp.-mediated transformation of rice cv. Kinmaze was performed as described by Toki (1997).

\section{Antibody production and immunoblotting.}

Polyclonal antibodies against OsFLS2 were generated in rabbits by immunization with keyhole limpet hemocyanin-conjugated OsFLS2 C-terminal peptide (CLKMSKLVGED). The immunoglobulin $\mathrm{G}$ (IgG) fraction of the resulting antiserum was affinity purified using peptide-conjugated resin. For immunoblotting, proteins were separated by sodium dodecyl sulfate polyacrylamide gel electrophoresis ( $7.5 \%$ acrylamide), then transferred to polyvinylidene difluoride membranes. After incubation with affinity-purified antibody, blots were developed with horseradish peroxidase-labeled anti-rabbit IgG using an ECL Plus chemiluminescence detection system (GE Healthcare, Bucks, U.K.).

\section{Cell death detection.}

Detection of cell death in cultured rice cells was performed by Evans blue staining as previously described (Che et al. 1999).

\section{Inoculation test.}

Inoculation of A. avenae to rice plant and counting the number of CFU were carried out as described previously (Che et al. 1999).

\section{ACKNOWLEDGMENTS}

We would like to thank the Rice Genome Resource Center (Japan) for providing the OsFLS2 cDNA clone and NASC stock center for the Arabidopsis T-DNA insertion line. We are also grateful to R. Imanaka for excellent technical support. This work was supported in part by Grants-inAid for Scientific Research (B) (17380067) and Creative Scientific Research (16GS0316 to A. Isogai) from the Ministry of Education, Culture, Sports, Science, and Technology, Japan.

\section{LITERATURE CITED}

An, C.-I., Sawada, A., Fukusaki, E., and Kobayashi, A. 2003. A Transient RNA Interference Assay System Using Arabidopsis Protoplasts. Biosci. Biotechnol. Biochem. 67:2674-2677. 
Asai, T., Tena, G., Plotnikova, J., Willmann, M. R., Chiu, W. L., GomezGomez, L., Boller, T., Ausubel, F. M., and Sheen, J. 2002. MAP kinase signalling cascade in Arabidopsis innate immunity. Nature 415:977983.

Baba, A., Hasezawa, S., and Syono, K. 1986. Cultivation of rice protoplasts and their transformation mediated by Agrobacterium spheroplasts. Plant Cell Physiol. 27:463-472.Bauer, Z., Gómez-Gómez, L., Boller, T., and Felix, G. 2001. Sensitivity of different ecotypes and mutants of Arabidopsis thaliana toward the bacterial elicitor flagellin correlates with the presence of receptor-binding sites. J. Biol. Chem. 276:45669-45676.

Bent, A. F., and Mackey, D. 2007. Elicitors, effectors, and $R$ genes: the new paradigm and a lifetime supply of questions. Annu. Rev. Phytopathol. 45:399-436.

Bolwell, G. P., Butt, V. S., Davies, D. R., and Zimmerlin, A. 1995. The origin of the oxidative burst in plants. Free Radic. Res. 23:517-532.

Che, F. S., Iwano, M., Tanaka, N., Takayama, S., Minami, E., Shibuya, N., Kadota, I., and Isogai, A. 1999. Biochemical and morphological features of rice cell death induced by Pseudomonas avenae. Plant Cell Physiol. 40:1036-1045.

Che, F. S., Nakajima, Y., Tanaka, N., Iwano, M., Yoshida, T., Takayama, S., Kadota, I., and Isogai, A. 2000. Flagellin from an incompatible strain of Pseudomonas avenae induces a resistance response in cultured rice cells. J. Biol. Chem. 275:32347-32356.

Chinchilla, D., Bauer, Z., Regenass, M., Boller, T., and Felix, G. 2006. The Arabidopsis receptor kinase FLS2 binds flg22 and determines the specificity of flagellin perception. Plant Cell 18:465-476.

Dunning, F. M., Sun, W., Jansen, K. L., Helft, L., and Bent, A. F. 2007. Identification and mutational analysis of Arabidopsis FLS2 leucine-rich repeat domain residues that contribute to flagellin perception. Plant Cell 19:3297-3313.

Felix, G., Duran, J. D., Volko, S., and Boller, T. 1999. Plants have a sensitive perception system for the most conserved domain of bacterial flagellin. Plant J. 18:265-76.

Fujiwara, S., Tanaka, N., Kaneda, T., Takayama, S., Isogai, A., and Che, F. S. 2004. Rice cDNA microarray-based gene expression profiling of the response to flagellin perception in cultured rice cells. Mol. PlantMicrobe Interact. 17:986-998.

Gómez-Gómez, L., and Boller, T. 2000. FLS2: an LRR receptor-like kinase involved in the perception of the bacterial elicitor flagellin in Arabidopsis. Mol. Cell 5:1003-1011.

Gómez-Gómez, L., and Boller, T. 2002. Flagellin perception: a paradigm for innate immunity. Trends Plant Sci. 7:251-256.

Grant, S. R., Fisher, E. J., Chang, J. H., Mole, B. M., and Dangl, J. L. 2006. Subterfuge and manipulation: type III effector proteins of phytopathogenic bacteria. Annu. Rev. Microbiol. 60:425-449.

Gurr, S. J., and Rushton, P. J. 2005. Engineering plants with increased disease resistance: what are we going to express? Trends Biotechnol. 23:275-282

Hann, D. R., and Rathjen, J. P. 2007. Early events in the pathogenicity of Pseudomonas syringae on Nicotiana benthamiana. Plant J. 49:607-618.
Ishiga, Y., Takeuchi, K., Taguchi, F., Inagaki, Y., Toyoda, K., Shiraishi, T., and Ichinose, Y. 2005. Defense responses of Arabidopsis thaliana inoculated with Pseudomonas syringae pv. tabaci wild type and defective mutants for flagellin $(\Delta f l i C)$ and flagellin-glycosylation $(\Delta o r f 1)$. J. Gen. Plant Pathol. 71:302:307.

Iwano, M., Che, F. S., Goto, K., Tanaka, N., Takayama, S., and Isogai, A. 2002. Electron microscopy analysis of the $\mathrm{H}_{2} \mathrm{O}_{2}$ accumulation preceding hypersensitive cell death induced by an incompatible strain of Pseudomonas avenae in cultured rice cells. Mol. Plant Pathol. 3:1-8.

Kadota, I., Ohuchi, A., and Nishiyama, K. 1991. Serological properties and specificity of Pseudomonas avenae Manns 1909 the causal agent of bacterial brown stripe of rice. Ann. Phytopathol. Soc. Jpn. 57:268-273.

Kadota, I., Mizuno, A., and Nishiyama, K. 1996. Detection of a protein specific to the strain of Pseudomonas avenae Manns 1909 pathogenic to rice. Ann. Phytopathol. Soc. Jpn. 62:425-428.

Kaneda, T., Fujiwara, S., Takai, R., Takayama, S., Isogai, A., and Che, F S. 2007. Identification of genes involved in induction of plant hypersensitive cell death. Plant Biotechnol. 24:191-200.

Lamb, C., and Dixon, R. A. 1997. The oxidative burst in plant disease response. Annu. Rev. Plant Physiol. Plant Mol. Biol. 48:251-275.

Robatzek, S., Bittel, P., Chinchilla, D., Köchner, P., Felix, G., Shiu, S. H., and Boller, T. 2007. Molecular identification and characterization of the tomato flagellin receptor LeFLS2, an orthologue of Arabidopsis FLS2 exhibiting characteristically different perception specificities. Plant Mol. Biol. 64:539-547.

Schwacke, R., and Hager, A. 1992. Fungal elicitors induce a transient release of active oxygen species from cultured spruce cells that is dependent on $\mathrm{Ca}^{2+}$ and protein-kinase activity. Planta 187:136-141.

Sheen, J. 2001. Signal transduction in maize and Arabidopsis mesophyll protoplasts. Plant Physiol. 127:1466-1475.

Taguchi, F., Shimizu, R., Nakagima, R., Toyoda, K., Shiraishi, T., and Ichinose, Y. 2003. Differential effects of flagellins from Pseudomonas syringae pv. tabaci, tomato and glycinea on plant defense response. Plant Physiol. Biochem. 41:165-174.

Takai, R., Kaneda, T., Isogai, A., Takayama, S., and Che, F. S. 2007. A new method of defense response analysis using a transient expression system in rice protoplasts. Biosci. Biotechnol. Biochem. 71:590-593.

Tanaka, N., Nakajima, Y., Kaneda, T., Takayama, S., Che, F. S., and Isogai, A. 2001. DNA laddering during hypersensitive cell death in cultured rice cell induced by an incompatible strains of Pseudomonas avenae. Plant Biotechnol. 18:295-299.

Tanaka, N., Che, F. S., Watanabe, N., Fujiwara, S., Takayama, S., and Isogai, A. 2003. Flagellin from an incompatible strain of Acidovorax avenae mediates $\mathrm{H}_{2} \mathrm{O}_{2}$ generation accompanying hypersensitive cell death and expression of $P A L, C h t-1$, and $P B Z 1$, but not of $L O X$ in rice. Mol. Plant-Microbe Interact. 16:422-428.

Toki, S. 1997. Rapid and efficient Agrobacterium-mediated transformation in rice. Plant Mol. Biol. Rep. 15:16-21.

Zipfel, C., Robatzek, S., Navarro, L., Oakeley, E. J., Jones, J. D., Felix, G., and Boller, T. 2004. Bacterial disease resistance in Arabidopsis through flagellin perception. Nature 428:764-767. 